\title{
Correlation of Hepatic Thyroxine 5'-Monodeiodination with Hexose Monophosphate Shunt in Young Rats
}

\author{
TAMOTU SATO, ${ }^{(38)}$ SHIGERU MARUYAMA, KOHKI SAIDA, AND IKURO TAKATA \\ Department of Pediatrics, School of Medicine, Kanazawa University, Takaramachi 13-1, Kanazawa City 920, Japan
}

\begin{abstract}
Summary
The role of NADPH and glutathione (GSH) in hepatic thyroxine (T4) 5 -deiodination and possible metabolic linkage between T4 converting system and hexose monophosphate shunt were studied in young rats during maturation. Low activity of T4 5'-deiodinase in young rats was enhanced 2-4-fold with the addition of $1 \mathrm{mM}$ NADPH and GSH in vitro, the effect of which was more prominent with NADPH than with GSH. The highest enhancement was observed at 2-3 wk of age, whereas basal $T 45^{\prime}$-deiodinase activity was gradually increased until 5-6 wk of age, decreasing to adult level thereafter. This change was associated with a rise in GSH and glycogen content in the liver and significantly correlated to the changes in glutathione reductase activity $(r=0.622, P<$ 0.001 ). In contrast, glucose-6-phosphate dehydrogenase (G6PD) activity remained depressed until 5 wk of age and rose sharply thereafter. Between T4 5'-deiodinase and G6PD activities after 6 wk of age, an inverse correlation was noted $(r=-0.749, P<0.01)$. A dose-response relationship between triiodothyronine (T3) production and NADPH in vitro showed similar age-related changes, whereas dose-dependency of T3 formation on GSH was decreasing with age, especially under the presence of $1 \mathrm{mM}$ NADPH.

These results indicate that: (1) NADPH and GSH are important cofactors of T4 conversion to T3; (2) NADPH appears to be more rate-limiting in the maturational process of the system; and (3) hexose monophosphate shunt plays a significant role in the regulation of T4 5 '-monodeiodination through NADPH and GSH formation.
\end{abstract}

\section{Speculation}

The physiologic hyperactivity of the thyroid gland during growth appears to be associated with an increased peripheral conversion of T4 to T3, which is closely correlated to the carbohydrate metabolism through hexose monophosphate shunt.

The extrathyroidal conversion of thyroxine (T4) to 3,5,3'-triiodothyronine (T3) has been established as the major pathway of $T 3$ production $(7,27,31)$. In the fetal and neonatal period, hepatic T4 5'-monodeiodination is extremely low, but rises promptly after birth $(13,15)$. Little is known, however, about the regulatory mechanism(s) of this reaction during the maturational process. It was suggested that reduced activity of $\mathrm{T} 45^{\prime}$-deiodination in the neonate was not due to the deficiency of the enzyme protein per $s e$, but rather to inactivation of existing enzymes or to a deficiency of cofactors (11). Importance of sulfhydryl (SH) groups in the reaction has been repeatedly stressed $(2-4,11,12,15,19,21,26$, 34,35 ), and nonprotein SH or glutathione (GSH) in tissue is regarded as an essential cofactor $(4,15,35)$. On the other hand, the close association of carbohydrate metabolism with T4 converting system has also been documented $(29,30,33)$. Taken together, it is postulated that there may be a metabolic linkage between hexose monophosphate shunt (HMS) and T4 mono- deiodinating system through NADPH-GSH cycle. In the present study, we attempted to elucidate the changes in the two pathways during maturation, and the role of NADPH and GSH in the hepatic conversion of $\mathrm{T} 4$ to $\mathrm{T} 3$, by sequential determination of the activity of glucose-6-phosphate dehydrogenase (G6PD) (EC 1.1.1.49), glutathione reductase (GSSG-R) (EC 1.6.4.2), T4 5'deiodinase and the content of GSH and glycogen in liver.

\section{MATERIALS AND METHODS}

Pregnant Wistar rats were provided with commercial rat chow and water ad libitum. On the 21-22nd day of pregnancy, 11-13 pups were delivered from each rats. Five to eight rats from different litters were used as the source of liver at weekly intervals up to 7 wk of age. Maternal rats served as control. Under ether anesthesia, the liver was removed, weighed and homogenized in 5 volume of ice cold $0.1 \mathrm{M}$ phosphate buffer ( $\mathrm{pH} 7.0$ ) containing $5 \mathrm{mM}$ EDTA with Teflon homogenizer. After centrifugation at $3000 \mathrm{rpm}$ for $10 \mathrm{~min}$ at $4^{\circ} \mathrm{C}$, the supernatant was immediately used for the following assays except for protein and glycogen analysis. NADP, NADPH, GSH, GSSG, glycogen, G6P, T4 and T3 were purchased from Sigma Chemical Co.

T4 5'-deiodinase assay. The activity was determined by the method of Chopra (10) under the presence or the absence of 1 $\mathrm{mM}$ NADPH, $1 \mathrm{mM}$ GSH and a combination of both in each sample. On each assay, duplicated samples of liver homogenate from an adult female rat or those from maternal rat after weaning ( 3 wk postpartum) were settled as control. One $\mathrm{ml}$ of assay mixture contained $400 \mu \mathrm{l}$ of $20 \%$ liver homogenate, $100 \mu \mathrm{l}$ of $\mathrm{T} 4(10 \mu \mathrm{g} / \mathrm{ml}$ in buffer) and $500 \mu$ of phosphate- EDTA buffer. When requested, $100 \mu \mathrm{l}$ of cofactor $(10 \mathrm{mM}$ in the buffer) was substituted. The mixture was usually incubated at $37^{\circ} \mathrm{C}$ for $60 \mathrm{~min}$. The reaction was stopped by the addition of $2 \mathrm{ml}$ of $95 \%$ ethanol. Generated T3 was extracted into ethanol (extraction rate; $85 \pm 5 \%$ ). After centrifugation, $10-50 \mu \mathrm{l}$ of the supernatant was used for T3 doubleantibody radioimmunoassay with commercially available kit (Eiken T3 RIA kit). To eliminate the effect of ethanol on the assay system, the equal amount of $63.3 \%$ ethanol was added to the standard curve. Endogenous T3 concentration was also measured in each sample and substracted from estimated T3 value. Generated $\mathrm{T} 3$ was expressed as $\mathrm{ng}-\mathrm{T} 3 / \mathrm{h} / \mathrm{mg}$-cytosol protein.

G6PD assay (6). Two and one-half $\mathrm{ml}$ of $0.1 \mathrm{M}$ Tris- $\mathrm{HCl}$ buffer ( $\mathrm{pH} 8.0$ ), $0.2 \mathrm{ml}$ of $0.1 \mathrm{M} \mathrm{MgCl}_{2}, 0.1 \mathrm{ml}$ of NADP Na-salt (10 mg/ $\mathrm{ml})$ and $0.1 \mathrm{ml}$ of $\mathrm{G} 6 \mathrm{P} \mathrm{Na}$-salt $(10 \mathrm{mg} / \mathrm{ml})$ were mixed and preincubated at $25^{\circ} \mathrm{C}$. The reaction was started with the addition of $20 \mu \mathrm{l}$ of supernatant of liver homogenate. Increase in adsorbance at $340 \mathrm{~nm}$ was recorded with Hitachi spectrophotometer Model 124. For calculation of NADPH formed, extinction coefficient of $E_{340}^{m M}=6.22$ was used and enzyme activity was reported as $\mu \mathrm{M}$ $\mathrm{NADPH} / \mathrm{min} / \mathrm{mg}$-protein.

GSSG-R assay (6). Incubation mixture consisted of $2.5 \mathrm{ml}$ of $0.1 \mathrm{M}$ Tris- $\mathrm{HCl}$ buffer ( $\mathrm{pH} 8.0), 0.1 \mathrm{ml}$ of EDTA $(10 \mathrm{mg} / \mathrm{ml}), 0.2$ $\mathrm{ml}$ of GSSG $(50 \mathrm{mg} / \mathrm{ml})$ and $0.05 \mathrm{ml}$ of NADPH Na-salt $(10 \mathrm{mg} /$ 
$\mathrm{ml}$ ), which was preincubated at $25^{\circ} \mathrm{C}$. The reaction was started with the addition of $20 \mu \mathrm{l}$ of supernatant of liver homogenate. Decrease in adsorbance at $340 \mathrm{~nm}$ was recorded and formed NADP was calculated in the same way as G6PD assay.

GSH content. Determination of GSH was performed by a modification of the method of Hissin and Hilf (16). One-half ml of $20 \%$ homogenate, $0.5 \mathrm{ml}$ of $25 \% \mathrm{HPO}_{3}$ and $1.0 \mathrm{ml}$ of $0.1 \mathrm{M}$ phosphate buffer ( $\mathrm{pH} 8.0$ ) containing 5 mM EDTA were mixed and centrifuged. To $100 \mu \mathrm{l}$ of the supernatant, $100 \mu \mathrm{l}$ of $o$-phthalaldehyde $(1 \mathrm{mg} / \mathrm{ml}$ in absolute methanol $)$ and $3.0 \mathrm{ml}$ of phosphateEDTA buffer were added. After standing for $15 \mathrm{~min}$ at room temperature, the solution was transferred to a quartz cuvette. Fluorescence at $420 \mathrm{~nm}$ was determined with the activation at 350 $\mathrm{nm}$. Standard GSH (2.5-10 nmoles/tube) was dissolved in phosphate-EDTA buffer just before use.

Liver glycogen was precipitated with 2 volume of ethanol, standing at $4^{\circ} \mathrm{C}$ overnight after $30 \% \mathrm{KOH}$ digestion. The precipitate was dissolved in $1.0 \mathrm{ml}$ of water and glycogen concentration was estimated by the method of Montogomery (24), using phenolsulfuric acid. Protein was estimated by the method of Lowry $e t$ al. (22), with bovine serum albumin as the standard. Statistical analysis was carried out by Student's $t$ test and the correlation coefficient was calculated by general formulas.

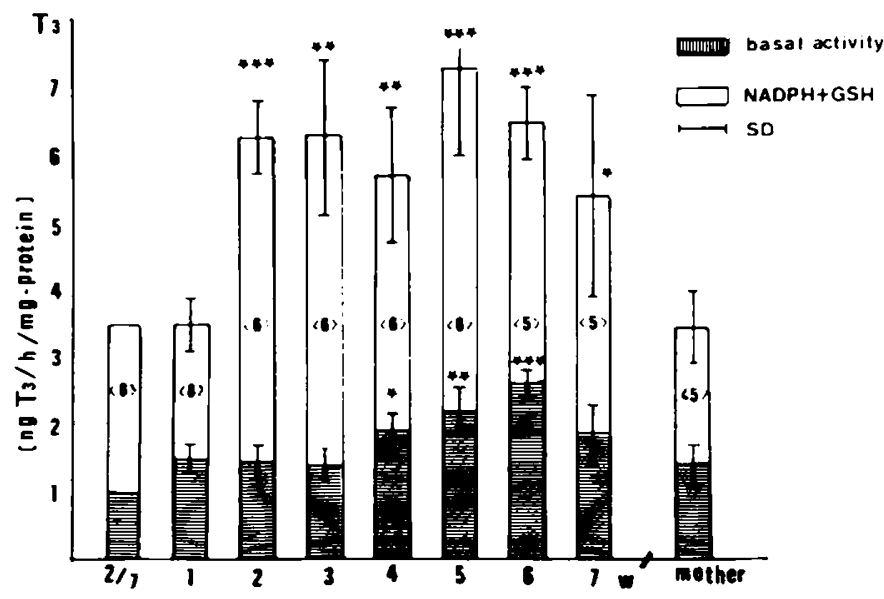

Fig. 1. Age-related changes in T4 $5^{\prime}$-deiodinase activity with (open column) or without (shaded column) supplement of $1 \mathrm{mM}$ NADPH and GSH. The activities of mother rats serve as controls. Number in parenthesis; number of rats. $2 / 7 ; 2$ days of age. ${ }^{*} P<0.05,{ }^{* *} P<0.01,{ }^{* * *} P<$ 0.001 vs control.

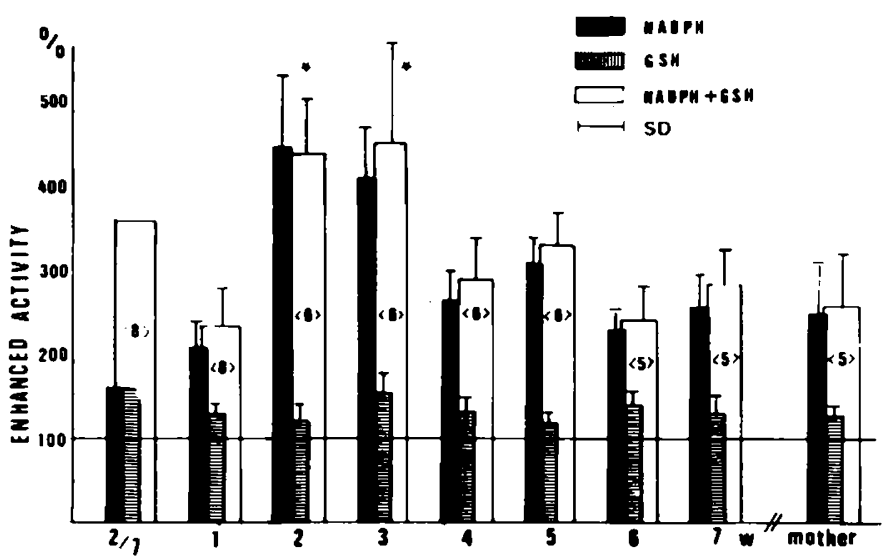

Fig. 2. Comparison of T4 5 '-deiodinase activation with $1 \mathrm{mM}$ NADPH (solid column) or $1 \mathrm{mM}$ GSH (shaded column) to the combined activation (open column), which are expressed in percent activity of basal level (without supplement). Number in parenthesis; number of rats. $2 / 7 ; 2$ days of age. ${ }^{*} P<0.01$ vs those of mother.

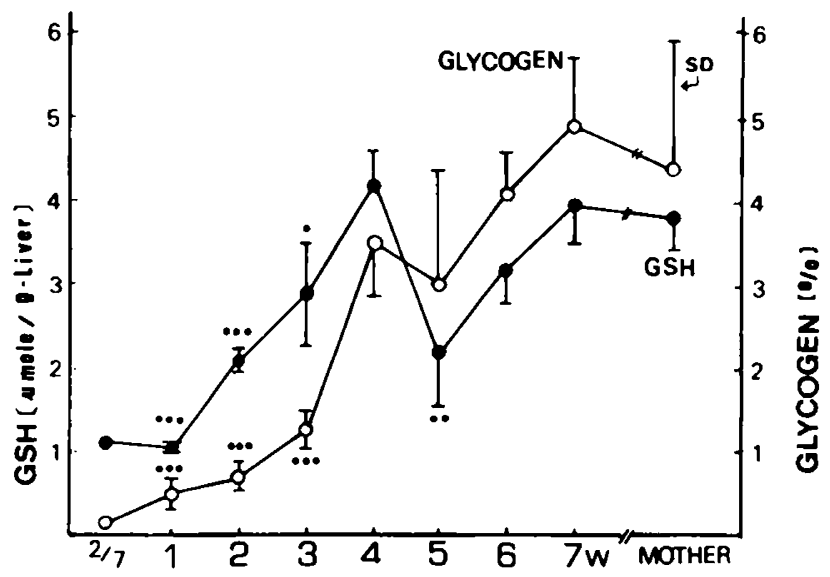

Fig. 3. Changes in hepatic glycogen (open circle) and GSH (solid circle) contents during maturation. Bar indicates mean \pm S.D. ${ }^{*} P<0.05,{ }^{* *} P<$ $0.01,{ }^{* * *} P<0.001$ vs those of mother rats.

\section{RESULTS}

Age-related changes in T4 $5^{\prime}$-deiodinase activity and effects of NADPH and/or GSH enrichment (Fig. $l$ and 2). The basal T4 5'deiodinase activity (without supplementation of NADPH or GSH) was low in the neonatal period. It rose gradually with age and reached a peak at 5-6 wk of age, decreasing to adult level thereafter. The addition of $1 \mathrm{mM}$ NADPH and GSH in vitro, however, markedly enhanced the activity. The relative enhancing rate was the greatest on 2-3 wk of age, but was diminished after 6 wk of age. The individual contribution of NADPH or GSH to the enhancement was shown in Figure 2. The additive effect of NADPH and GSH was apparent only in the neonate. Most of the activating effect was due to NADPH, although a small but definite effect was noted with $1 \mathrm{mM} \mathrm{GSH}$. These data suggest that NADPH exerts a significant effect on $\mathrm{T} 3$ generating system, and reduced production of $\mathrm{T} 3$ during the neonatal period may be due partially to the deficiency of NADPH and GSH.

GSH and glycogen contents in liver (Fig. 3). Changes in GSH and glycogen concentration were almost parallel to each other. Both were extremely depressed in the neonatal period and rose progressively between 2-4 wk of age. The cause of transient decrease at 4-5 wk of age was not apparent, but it may be due to the effect of weaning.

Changes in the activity of GSSG-R and G6PD (Fig. 4 and 5). The GSSG-R activities were significantly reduced from 2 days to 3 wk of age $(P<0.001$ versus adult), which increased rapidly above adult level during 4-6 wk of age. These changes were approximately parallel to the mean value of T3 production in vitro. In contrast, G6PD activities remained depressed until 5 wk of age, rising sharply thereafter. It is noteworthy that $\mathrm{T} 4$ deiodinating activity was reciprocally decreasing in the period.

Figure 5 shows the relation between generated T3 and GSSG$R$ or G6PD activities. As mentioned above, there was a significant correlation between T3 formation and GSSG-R activities ( $r=$ $0.622, P<0.001$ ). G6PD activities before $5 \mathrm{wk}$ of age were low and relatively stable, whereas those after $6 \mathrm{wk}$ of age were inversely correlated with generated T3 $(r=-0.749, P<0.01)$. This suggests that response of T4 $5^{\prime}$-deiodinase to NADPH may be different with age. This possibility was tested in vitro.

Dose-response relation of T3 formation to NADPH and GSH (Fig. 6). Dose-response curve of T3 production to NADPH showed a plateau at the concentration of $0.25-0.5 \mathrm{mM}$ NADPH. The level of plateau was low in $1 \mathrm{wk}$ of age; the highest in $3 \mathrm{wk}$ of age; and decreased again with age. The addition of $1 \mathrm{mM}$ GSH to NADPH doses did not affect the pattern of this age-related change. In contrast, a linear dose-response relationship was noted in the range of 0.5-5 mM GSH, but the degree of activation was not so great as that of NADPH. The supplement of $1 \mathrm{mM}$ NADPH to graded doses of GSH again markedly enhanced T3 formation, 
which eliminated the dose-dependency of T3 production on GSH in older and adult rats. These results indicate that $\mathrm{T} 45^{\prime}$-monodeiodination in young rats is dependent on both NADPH and GSH, whereas in older rats NADPH is more rate-limiting than GSH. Furthermore, NADPH exerts its effect by direct stimulation of T4 5'-deiodinase rather than by increase in GSH formation.

\section{DISCUSSION}

Peripheral conversion of $\mathrm{T} 4$ to $\mathrm{T} 3$ is modulated by several conditions, such as thyroid hormone excess and deficiency $(2,5$, $15,17,18)$, stress $(8,9)$, age $(13,15,36)$, sex $(14)$ and dietary effects $(3,4,12,15,19,29,30,33)$. In each situation, however, the mechanism by which conversion of $\mathrm{T} 4$ to $\mathrm{T} 3$ is regulated may be different. Carbohydrate deprivation reduced $\mathrm{T} 3$ formation by a reduction in the hepatic content of endogenous cytosolic thiol compounds (principally GSH) $(20,23)$, restoration of which can improve the rate of conversion in vitro $(4,15)$. During starvation, lack of glucose substrate and decreased activity of G6PD and malate dehydrogenase result in a decrease in cytosol NADPH (1, $25,28,32)$. NADPH is an essential cofactor of GSH formation, which is primarily generated by HMS. Considering these data, it is suggested that there may be a metabolic linkage between HMS

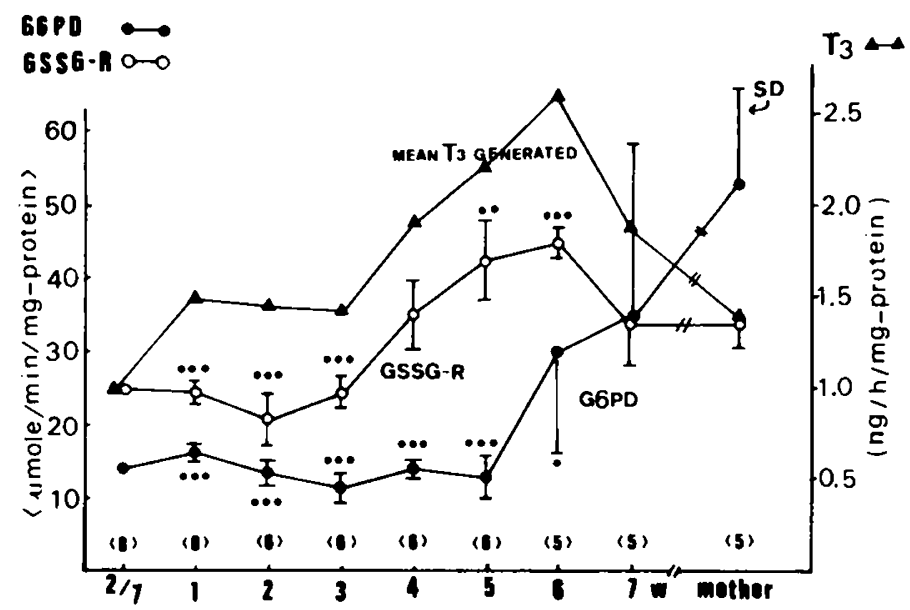

Fig. 4. Maturational changes in GSSG-R (open circle) and G6PD (solid circle) activities in liver. Mean values of generated T3 (triangle) are also shown, which are approximately parallel to GSSG-R activities. ${ }^{*} P<0.05$, ${ }^{* *} P<0.01,{ }^{* * *} P<0.001$ vs those of mother rats.

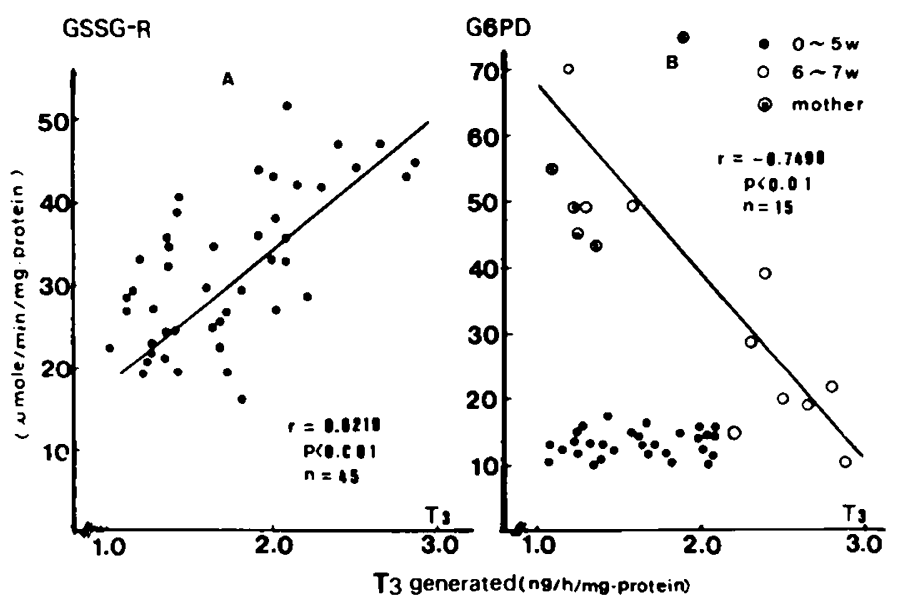

Fig. 5. (A) Correlation between T4 5'-deiodinase and GSSG-R activities. A statistically significant correlation is noted $(r=0.622, P<0.001)$. (B) Correlation between T4 5'-deiodinase and G6PD activities. (Solid circle) 0-5 wk of age; (open circle) 6-7 wk of age; (double circle) mother rats. An inverse correlation is obtained after $6 \mathrm{wk}$ of age $(r=-0.749, P$ $<0.01$ ).

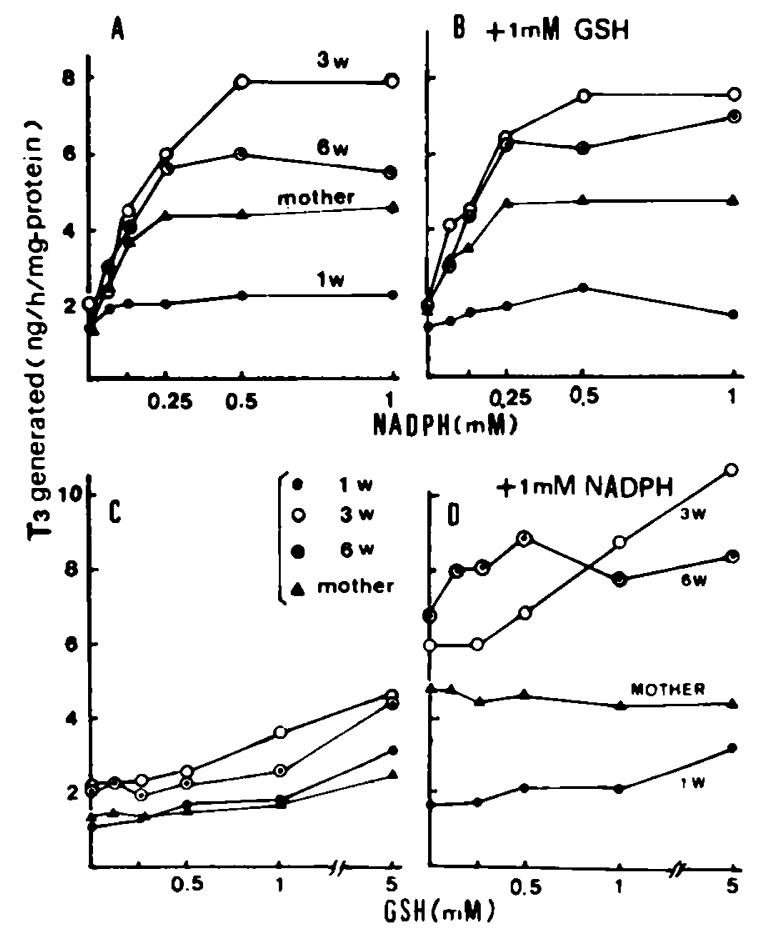

Fig. 6. Dose-response curves of T3 production to NADPH with (B) or without (A) $1 \mathrm{mM}$ GSH. Lower panel; those to GSH with (D) or without (C) $1 \mathrm{mM}$ NADPH. (Solid circle) $1 \mathrm{wk}$ of age; (open circle) 3 wk of age; (double circle) $6 \mathrm{wk}$ of age; (triangle) mother rats.

and hepatic T4 $5^{\prime}$-deiodination (15). In the fetus and neonate, the reduced conversion of $\mathrm{T} 4$ to $\mathrm{T} 3$ is reported to be due to the diminished content of cofactors rather than the amount of T4 5'deiodinase per se $(11,15)$. The results of the present study demonstrate that the maturational changes in HMS are closely associated with those in $\mathrm{T} 4$ converting system. The addition of NADPH and/or GSH to liver homogenates of young rats enhanced T3 generation 2-5-fold. Age-related increase in hepatic GSH content and in GSSG-R activity is also parallel to the change in T4 5'-deiodinating activity. Lower activity of G6PD in young rat liver was correlated with greater enhancement of $\mathrm{T} 3$ production by exogenous NADPH enrichment in vitro. These indicate that NADPH and GSH are important cofactors of T4 conversion to T3.

There is considerable difference, however, between the effect of NADPH and that of GSH. The magnitude of activation was always greater with NADPH than with GSH. The additive effect of GSH to NADPH on T3 production was apparent only in young rats. A dose-response curve of $\mathrm{T} 3$ generation to increasing doses of GSH was also blunted with advance of age. Probably, this is due to the endogenous GSH level, which seems to be present in enough amounts in older rat liver. These findings suggest that NADPH is more rate-limiting than GSH in T4 converting system during maturation. Furthermore, NADPH is supposed to affect directly the thiol radicals in the enzyme protein rather than via formation of GSH. In this regard, it is of interest that a reciprocal change was found between generated T3 and G6PD activities after $6 \mathrm{wk}$ of age. This is a rather unexpected result. The increase in G6PD activity in this period may be the reflection of an accelerated turnover of NADPH in liver, which can result in the reduction of T3 production. Another possible explanation is that hormonal influence related to sexual maturation may be involved in the fall of $\mathrm{T} 3$ production during this period, because the sexual difference in T4 monodeiodination has been apparent after puberty (14). However, the exact cause of decrease in $\mathrm{T} 3$ formation after puberty remains to be elucidated in future.

In summary, the present study demonstrates that there is a close relationship between HMS and the converting system of T4 to T3 
through the formation of NADPH and GSH during the maturational process.

\section{REFERENCES AND NOTES}

1. Anderson, J. and Hollifield, G.: The effects of starvation and refeeding on hexose-monophosphate shunt enzyme activity and DNA, RNA and nitrogen content of rat adipose tissue. Metabolism, 15: 1098 (1966).

2. Balsam, A., Sexton, F., and Ingbar, S. H.: The effect of thyroidectomy, hypophysectomy and hormone replacement on the formation of triiodothyronine from thyroxine in rat liver and kidney. Endocrinology, 103: 1759 (1978).

3. Balsam, A. and Ingbar, S. H.: The influence of fasting, diabetes and several pharmacological agents on the pathways of thyroxine metabolism in rat liver. J. Clin. Invest., 62: 415 (1978).

4. Balsam, A. and Ingbar, S. H.: Observations on the factors that control the generation of triiodothyronine from thyroxine in rat liver and the nature of the effect induced by fasting. J. Clin. Invest., 63: 1145 (1979).

5. Balsam, A., Sexton, F., and Ingbar, S. H.: The mechanism of impaired in vitro generation of 3,5,3'-triiodothyronine from thyroxine in livers of hypothyroid rats. Endocrinology, 105: 1115 (1979).

6. Bergmeyer, H. V.: In: Methods of enzymatic analysis, 2nd ed. vol. 1: pp 456-465 (Academic Press Inc, New York and London, 1974).

7. Braverman, L. E., Ingbar, S. H., and Sterling, K.: Conversion of thyroxine to triiodothyronine in athyrotic human subjects. J. Clin. Invest., 49: 855 (1970).

8. Burr, W. A., Black, E. G., Griffiths, R. S., and Hoffenberg, R.: Serum triiodothyronine concentrations after surgical operation. Lancet, II: 1277 (1975).

9. Carter, J. N., Corcoran, J. M., Eastman, C. J., and Lazarus, L.: Effect of severe chronic illness on thyroid function. Lancet, II: 971 (1974).

10. Chopra, I. J.: A study of extrathyroidal conversion of thyroxine (T4) to $3,3^{\prime}, 5-$ triiodothyronine (T3) in vitro. Endocrinology, 101: 453 (1977).

11. Chopra, I. J.: Sulfhydryl groups and the monodeiodination of thyroxine to triiodothyronine. Science, 199: 904 (1978).

12. Chopra, I. J.: Alterations in monodeiodination of iodothyronine in the fasting rats; effects of reduced nonprotein sulfhydryl groups and hypothyroidism. Metabolism, 29: 161 (1980).

13. Harris, A. R. C., Fang, S. L., Prosky, J., Braverman, L. E., and Vagenakis, A. G.: Decreased outer ring monodeiodination of thyroxine and reverse triiodothyronine in the fetal and neonatal rat. Endocrinology, 103: 2216 (1978).

14. Harris, A. R. C., Vagenakis, A. J., and Braverman, L. E.: Sex-related difference in outer ring monodeiodination of thyroxine and 3,3',5'-triodothyronine by rat liver homogenates. Endocrinology, 104: 645 (1979).

15. Harris, A. R. C.. Fang, S. L., Hinerfeld, L., and Braverman, L. E.: The role of sulfhydryl groups on the impaired hepatic 3',3,5-triiodothyronine generation from thyroxine in the hypothyroid, starved, fetal and neonatal rodent. J. Clin Invest., 63: 516 (1979).

16. Hissin, P. J. and Hilf, R.: A fluorometric method for determination of oxidized and reduced glutathione in tissue. Analy. Biochem., 74: 214 (1976).

17. Kaplan, M. M. and Utiger, R. D.: Iodothyronine metabolism in liver and kidney homogenates from hyperthyroid and hypothyroid rats. Endocrinology, 103: $156(1978)$.

18. Kaplan, M. M.: Changes in the particulate subcellular component of hepatic T4 $5^{\prime}$-monodeiodination in hyperthyroid and hypothyroid rats. Endocrinology 105: 548 (1979).

19. Kaplan, M. M.: Subcellular alterations causing reduced hepatic thyroxine 5 monodeiodinase activity in fasted rats. Endocrinology, 104: 588 (1979).

20. Lauterburg, B. H. and Michell, J. R.: Increased hepatic glutathione (GSH) synthesis during fasting. Gastroenterology (Abstract), 78: 1311 (1980).

21. Leonard, J. L. and Rosenberg, I. N.: Thyroxine 5 '-deiodinase activity of rat kidney: observations on activity by thiols and inhibition by propylthiouracil Endocrinology, 103: 2137 (1978).

22. Lowry, O. H., Rosebrough, N. J., Farr, A. L., and Randall, R. J.: Protein measurement with Folin phenol reagent. J. Biol. Chem., 193: 256 (1951).

23. Maruyama, E., Kojima, K., Higashi, T., and Sakamoto, Y.: Effect of diet on live glutathione and glutathione reductase. J. Biochem. (Tokyo), 63: 398 (1968).

24. Montogomery, R.: Determination of glycogen. Arch. Biochem. Biophys., 67: 378 (1957).

25. Nace, C. S. and Szepesi, B.: Dietary fatty acids and the control of glucose-6phosphate dehydrogenase and malic enzyme in the starved-refed rat. J. Nutr., 106: 285 (1976).

26. Oppenheimer, J. H., Schwartz, H. L., and Surk, M. I.: Propylthiouracil inhibits the conversion of L-thyroxine to L-triiodothyronine. J. Clin. Invest., 5I: 2493 (1972).

27. Pittman, C. S., Chambers, J. B. Jr., and Read, V. H.: The extrathyroidal conversion rate of thyroxine to triiodothyronine in normal man. J. Clin. Invest., 50: 1187 (1971).

28. Rudack, D., Chisholm, E. M., and Holten, D.: Rat liver glucose-6-phosphate dehydrogenase regulation by carbohydrate diet and insulin. J. Biol. Chem., 246: 1249 (1971)

29. Spaulding, S. W., Chopra, I. J., Serwin, R. S., and Lyall, S. S.: Effect of caloric restriction and dietary composition on serum $\mathrm{T} 3$ and reverse $\mathrm{T} 3$ in man. J. Clin. Endocrinol. Metab., 42: 197 (1976).

30. Suda, A. K., Pittman, C. S., Shimizu, T., and Chambers, J. B. Jr.: The production and metabolism of 3,5,3'-triiodothyronine and 3,3', ' -triiodothyronine in normal and fasting subjects. J. Clin. Endocrinol. Metab., 47: 1311 (1978).

31. Surk, M. 1. and Oppenheimer, J. H.: Formation of iodoprotein during the peripheral metabolism of 3,5,3'-triiodo-L-thyronine ${ }^{125} \mathrm{I}$ in the euthyroid man and rat. J. Clin. Invest., 48: 685 (1969).

32. Szepesi, B., Berdanier, C. D., Diachenko, S. K., and Moser, P. B.: Effect of length of starvation, refeeding and azaguanine on serum insulin and NADP-linked dehydrogenases of rat liver. J. Nutr., 101: 1147 (1971).

33. Vagenakis, A. G., Burger, A., Pornay, G. I. Rudolph, M. O'Brian, J. T., Azizi, F., Arky, R. A., Nicod, P., Ingbar, S. H., and Braverman, L. E.: Diversion of peripheral thyroxine metabolism from activating to inactivating pathways during complete fasting. J. Clin. Endocrinol. Metab., 41: 191 (1975).

34. Visser, T. J., Van der Does-Tobe, I., Docter, R., and Hennemann, G.: Conversion of thyroxine into triiodothyronine by rat liver homogenate. Biochem. J., 150: 489 (1975).

35. Visser, T. J., Van der Does-Tobe, I., Docter, R., and Hennemann, G.: Subcellular localization of a rat liver enzyme converting thyroxine into tri-iodothyronine and possible involvement of essential thiol groups. Biochem. J., 157: 479 (1976)

36. Wu, S. Y., Klein, A. H., Chopra, I. J., and Fisher, D. A.: Alterations in tissue thyroxine 5 -monodeiodinating activity in the perinatal period. Endocrinology, 105: 548 (1978).

37. This work is supported in part by the Grant from the Ministry of Education in Japan.

38. Request for reprints should be addressed to: Dr. Tamotu Sato, Department of Pediatrics, School of Medicine, Kanazawa University, Takaramachi 13-1, Kanazawa City, 920, Japan.

39. The authors thank Mr. Keiichi Nomura and Dr. Noboru Nakai for their stimulating suggestions and comments on this work.

40. Received for publication July 23, 1981.

41. Accepted for publication October 21, 1981. 